HOW SIMILARITY TO PEERS AND THE SUPERVISOR INFLUENCES ORGANIZATIONAL ADVANCEMENT IN DIFFERENT CULTURES

JOHN SCHAUBROECK

Drexel University

Department of Management

LeBow College of Business

33rd \& Arch Streets

Philadelphia, PA, USA, 19014

Phone: 1-215-895-1792

Fax: 1-215-895-2891

E-mail: john.m.schaubroeck@drexel.edu

SIMON S.K. LAM

School of Business

The University of Hong Kong

Pokfulam Road, Hong Kong

Phone: (+852) 28591008

Fax: (+852) 28585614

E-mail: simonlam@business.hku.hk

December 14, 2001 


\title{
HOW SIMILARITY TO PEERS AND THE SUPERVISOR INFLUENCES ORGANIZATIONAL ADVANCEMENT IN DIFFERENT CULTURES
}

\begin{abstract}
This study tested hypotheses concerning how similarity of personality traits between promotion candidates and their peers and supervisors influence promotion decisions in different work unit cultures. Candidates working in units with higher mean levels of reported individualism were more likely to be chosen for promotion to the extent their personality characteristics were similar to their unit peers. Candidates in units in which collectivistic orientations predominated did not show such peer personality similarity influence, but for them supervisor/subordinate personality similarity was a significant predictor of advancement. Variables indexing behavioral integration between candidates and their peers and supervisors partially mediated the influence of personality similarity on promotion. Demographic similarity had little influence on promotion decisions. We discuss the implications of these findings for understanding similarity effects and for increasing the validity of promotion decisions.
\end{abstract}




\section{HOW SIMILARITY TO PEERS AND THE SUPERVISOR INFLUENCES ORGANIZATIONAL ADVANCEMENT IN DIFFERENT CULTURES}

As noted by Wayne et al. (1997), despite the critical importance of promotions very little is known about the factors underlying these events compared to other types of human resource decisions. Whereas studies have found that qualifications and demographic traits such as race and gender were significant influences on advancement (Fox \& Butterfield, 1994; James, 2000), the empirical literature on promotions has not fully captured what are, by many accounts, the key social influences on promotion. Specifically, often assessments of promotability appear to be influenced by similarity to the decision maker (Ferris \& Judge, 1991).

Much recent research in organizational behavior has examined the negative influence of being different from other persons on important individual outcomes, such as social integration within the work unit, performance ratings, and organizational commitment (see Williams \& O’Reilly, 1998). Being different from others may also impede career advancement. Research in human resource management has observed that perceived similarities between applicants and their interviewers often are positive factors in selection decisions. Once in the organization, being similar to one's principals has been found to have a favorable influence on performance ratings (Tsui \& O’Reilly, 1989; Turban \& Jones, 1988). Qualitative and quantitative evidence suggests that having a social or educational background that is shared with decision makers predicts advancement (Markham, Harlan, \& Hackett, 1987; Farh, Tsui, Xin, \& Cheng, 1998).

Much of the previous research on similarity effects has focused upon demographic variables such as racial or ethnic category, gender, and length of organizational tenure. Studies in other areas have observed that deep-level characteristics that are less obvious to observers, 
such as personality, are prominent in decision makers' assessments of individual effectiveness and "fit" (Ferris \& Judge, 1991). Personality differences may become manifest by conflicts between the behavioral styles of coworkers that create difficulties in their interpersonal interactions. Harrison, Price, and Bell (1998) noted that similarities on deep-level characteristics such as attitudes, values, and behavioral tendencies tend to have more lasting influences on processes and outcomes than surface-level differences such as those that relate to race, gender, and organizational tenure. Thus similarities (and differences) in personality may have significant implications for the quality of relationships among coworkers. Previous research suggests that prevailing cultural norms of individualism-collectivism (I-C) have an important influence on coworker integration, and I-C also influences the degree to which similarity influences other employee outcomes (see Chatman, Polzer, Barsade, \& Neale, 1998). In this study we examined how I-C moderates the effects of promotion candidates' personality similarities with their work unit peers and supervisors on promotion decisions.

\section{Influences of Peer Dissimilarity}

Behavioral integration and similarity-attraction approaches to understanding effects of individual similarity/dissimilarity posit that being similar to others facilitates more effective interaction (e.g., Chatman et al., 1998; O’Reilly, Caldwell, \& Barnett, 1989; K.G. Smith, K.A. Smith, Olian, Sims, O’Bannon, \& Scully, 1994). Persons who share certain traits, even if they are not conscious of them, are more inclined to interact with one another effectively because they use common referents in perceiving, interpreting, and acting on social information. Thus indices of behavioral integration, a "meta-construct" related to communication quality and collaboration among members of a group (Hambrick, 1994: 189), have proved to be key mediators linking workgroup homogeneity to group performance. Social integration refers to "the degree to which 
an individual is psychologically linked to others in a group" (Hambrick, 1994: 189).

Commonalities among group members make it easier for them to identify with one another, and the attraction that results from this (social integration) is positively associated with variables measuring the more substantive (in terms of work process) concept of behavioral integration.

Much of the research finding that behavioral integration mediates demographic dissimilarity effects has been conducted at the group aggregate level (Chatman \& Flynn, 2001; Jehn, Northcraft, \& Neale, 1999; O’Reilly, Caldwell, \& Barnett, 1989; K.G. Smith et al., 1994). But these processes may also operate at the level of individual dyads, as demonstrated in other research (Chatman \& Barsade, 1995; Chatman et al 1998). Workgroup members who have personalities that are different from their peers may struggle to communicate effectively with them and achieve a cooperative relationship. The individuals within a workgroup who are most similar to their peers may therefore be more readily perceived as effective performers and potential leaders. As noted by James, similarities to one's peers may enhance one's accumulation of social capital, and social capital is an established predictor of organizational advancement. "While strong tie relationships to superiors may be important, strong ties to peers and subordinates can be equally valuable in that having them may demonstrate an ability to effectively interact with and/or manage others, a trait that may be desirable to top managers when making promotion decisions" (2000: 497). The importance of effective interactions with peers to advancement is evidenced by peer evaluations' superior success, compared to assessor ratings and cognitive ability scores, in predicting individuals' advancement within organizations (T.H. Shore, L.M. Shore, \& Thornton, 1992).

Research on social groups outside of work settings has indicated that members' similarity to group peers on behavioral tendencies (e.g., assertive versus passive) is positively related to 
their informal group status as reflected by peer ratings of popularity and credibility and evidence of exclusion from peripheral group activities (e.g., Wright, Giammarino, \& Parad, 1986). Such processes may influence supervisors' judgments of promotion potential in two ways. Group members with characteristically different ways of perceiving and responding to events (i.e., personality dissimilar members) may come to believe that their lower informal status within the group lessens their chances of leading the group effectively or of being recognized as potentially effective leaders. This becomes a self-fulfilling prophecy as such individuals are discouraged from demonstrating their interest in and potential for advancement. In addition, having a different approach to perceiving, interpreting, and responding to events limits the common referents needed to effectively integrate with others. Over time, ineffective interactions lead peers to ascribe low status to the individual, and this low status weakens further his or her ability to have effective interactions with them. All of these potential mechanisms lead to the hypothesis that having a personality that is similar to one's peers enhances behavioral integration and this increases one's potential of being recognized by observers as a potentially effective leader.

Hypothesis 1 . Personality similarity between promotion candidates and their work unit peers will be positively associated with being selected for a promotion.

Hypothesis 2. The effect of peer personality similarity on being chosen for a promotion will be mediated by rated job performance and behavioral integration with peers.

\section{Influences of Supervisor/Subordinate Personality Similarity}

The similarity-attraction model suggests that raters have self-based schemas about performance and social relationships that reinforce their own favorable self-image, and these schemas positively bias their evaluations of self-similar others (Byrne, 1971). In addition, 
similarity provides the supervisor a measure of trust that the subordinate will behave as he or she wishes even when monitoring and incentives are not possible. From this perspective, principals seek to build relationships with similar subordinates because they better trust similar persons to perform effectively and in ways that reinforce their own personal interests, even after the bosssubordinate relationship concludes (see Jackson, et al., 1991; Tsui \& O’Reilly, 1989). Thus supervisor/similarity effects on promotion decisions may reflect informational biases stemming from how they attend to and recall subordinates' performance, as well as motivational biases that support their personal interests.

In a study conducted by Wayne, Liden, Graf, \& Ferris (1997), supervisors held more favorable social schemas about subordinates they perceived as being more similar to themselves. This appeared to explain why subordinates reporting higher leader-member exchange (LMX) were judged as being more promotable. LMX studies compare the effects of supervisors' relationships with preferred subordinates, characterized by trust and personal commitment, with relationships characterized by transactional exchange. In this study we tested both LMX and a separate measure of supervisor communication as mediators of supervisor/subordinate personality similarity effects on promotion decisions. LMX indexes generally ask the subordinate to report on their supervisors' personal trust and commitments to the subordinate, whereas supervisor communication referred to the extent a subordinate reported interacting smoothly with the supervisor. These variables represent distinct aspects of the "meta-construct" of behavioral integration (Hambrick, 1994: 189) as it relates to one's relationship with the supervisor.

Supervisor/subordinate personality similarity may also increase promotion potential because of a desire of evolving management groups to maintain or enhance their influence by 
ensuring that new members of their group adhere to the norms they have established. Managers can achieve this goal by limiting new management hires and promotees to persons who are similar to themselves. Along with the social and behavioral integration advantages of similarity, this homosocial reproduction process (Kanter, 1977) is widely posited to explain similarity effects. Eagleson, Waldersee, and Simmons (2000) found evidence for this effect in a simulation study. Managers selected for management positions candidates they learned were more similar to themselves in leadership style. This relationship between supervisor/subordinate personality similarity and promotion decisions suggests a specific type of motivational bias. This would be reflected by a relationship between similarity and promotion that is not mediated by behavioral integration with the supervisor. However, within this process managers may give self-similar subordinates higher performance ratings in order to increase their promotion prospects.

Hypothesis 3. Personality similarity between promotion candidates and their supervisors will be positively associated with promotion decisions.

Hypothesis 4. Job performance, LMX, and supervisor communication will each partially mediate the effect of supervisor/subordinate personality similarity on promotion decisions.

\section{Cultural Context of Promotion Decisions}

Because promotion decisions are inherently social, the influences upon them may be expected to differ depending on the institutional framework of the society in which they occur. Cultural institutions of a society are transferred to the organizations that operate in them, and thus they determine how members interact and approach decisions. Because of its implications for social and behavioral integration, individualism-collectivism (I-C) has been cited as an important moderator of the effects of peer similarity on group and interpersonal interaction 
(Chatman \& Barsade, 1995; Chatman et al., 1998). When societies are sampled, most of their members tend to affirm beliefs and values that are located near the same place on a continuum ranging from high individualism to high collectivism. Of course, even in societies where an orientation toward extreme collectivism or individualism is the norm, there is considerable individual variation around the modal trends in these beliefs and values. These differences are believed to stem from the unique developmental histories of individuals as well as their memberships in smaller groups (e.g., families, religious groups) that support beliefs and values that may differ from the society at large. These sources of variation in cultural beliefs and values enable organizations and work units to exhibit distinct cultures. Organizations are seen to attract and select persons who attest to particular beliefs and values, and persons whose beliefs and values are appreciably different from others with whom they work may leave the organization either voluntarily or involuntarily because of the social difficulties and disappointment created by these differences in outlook (Schneider, Goldstein, \& D.B. Smith, 1995). Other research suggests that employees' general beliefs and values tend to converge over time with those of their coworkers (Kohn \& Schooler, 1982), and that management practices can encourage a more individualistic or collectivistic orientation among employees (see Chatman \& Barsade, 1995; Chatman et al., 1998). Thus, whereas organizations' memberships tend to reflect the broader societal culture, they are not random samples of the society. Provided they are physically separated, differences in leadership style are not stifled, and their historical circumstances have been somewhat different, even the subunits of a larger organization may have unique cultures (Trice \& Beyer, 1993).

Cultural differences in peer personality similarity effects. Compared to individualistic cultures, collectivistic organizational cultures maintain higher agreement about norms of 
behavior, exhibit greater adherence to these norms, and provide quick and punitive sanctions for violations (Chatman et al., 1998). These factors prevent dissimilarities among members from impeding the quality of interaction. Chatman et al. (1998) found that under individualistic norms, demographically similar workgroup members communicated more frequently, reported less interpersonal conflict, and exhibited higher productivity compared to similar workgroup members operating under collectivistic norms.

One likely reason for the smoother workgroup integration among diverse individuals in collectivistic cultures is that a common work unit or organizational affiliation will often suffice to establish a common identity (Earley, 1993; Chatman \& Barsade, 1995). In other words, social integration is a foundation for behavioral integration in all cultures, but in collectivistic cultures social integration is obtained without need for personality similarity. In addition, lateral relationships among peers are perceived as being less critical for success in collectivistic cultures because these cultures do not emphasize decentralization of authority but rather rely on hierarchy for coordination and control (Bond \& Hwang, 1995; P.B. Smith, Peterson, \& Wang, 1996). Under individualistic norms, on the other hand, people tend to emphasize individual differences. In such cultures managers cannot take for granted the cooperation among lower-level participants that is needed to complete work, satisfy customers, and resolve task problems. The smoother integration with one's peers that may follow from having a similar personality may thus be more salient and contribute more strongly to perceived effectiveness than it does in collectivistic cultures. Thus in individualistic work unit cultures peer integration may have a direct influence on promotion decisions because decision makers (including the supervisor) recognize how the candidate's peer relationships reflect traits that may make him or her effective in a leadership role. This aspect of the peer integration - promotion relationship is not expected 
to be mediated by the candidate's perceived performance on technical aspects of his or her current job.

As noted above, managers in individualistic work unit cultures follow stronger norms for decentralizing authority to individual subordinates and teams. In collectivistic cultures managers are more concerned about subordinates' loyalty and adherence to hierarchical authority than they are with their horizontal relationships; indeed, in some cases a subordinate with high status among peers may even be perceived as threatening to a manager's authority if the manager does not fully trust him or her (Bond \& Hwang, 1995; P.B. Smith, Peterson, \& Wang, 1996). Such subordinates are likely to be perceived as ineffective in these contexts as well as being less capable of promotion. Thus the influence of peer integration on promotion decisions, limited to more individualistic work unit cultures, may be partially mediated by the performance ratings provided by supervisors.

Hypothesis 5 . The effects of peer personality similarity on promotion decisions will be moderated by individualism-collectivism.

Hypothesis 5a. The effects of peer personality similarity on peer integration will be stronger in individualistic work unit cultures.

Hypothesis 5b. The effects peer integration on promotion decisions will be stronger in individualistic work unit cultures.

Hypothesis $5 \mathrm{c}$. Job performance ratings will partially mediate the effects of peer integration on promotion decisions.

Cultural differences in supervisor/subordinate personality similarity effects. The types of collectivistic norms examined by Chatman et al. (1998) in studying peer similarity influences on behavior are represented along the horizontal dimension of collectivism. Horizontal collectivism 
refers to an emphasis on personal equality and interdependence over merit and competition. Vertical collectivism emphasizes hierarchy and willing adherence to the legitimate authority of others (Triandis \& Gelfand, 1998). This is often referred to as power distance. In East Asian cultures vertical and horizontal collectivism blend together. Fiske, Kitayama, Markus, \& Nisbett (1998) suggested that East Asian societies can be broadly distinguished from European American societies based on the formers' typical emphasis on vertical and horizontal collectivism compared to the high vertical and horizontal individualism found in Europe and North America. Vertically collectivistic norms provide power-holders with considerable discretion over the criteria they use in evaluating subordinates. For example, much anecdotal evidence suggests that in Chinese societies, loyalty to the supervisor is critical to organizational advancement, and managers use particularistic criteria, or personalism, in judging employee competence (Tsui \& Farh, 1997; Farh et al, 1998). Personalism refers to the norm of allowing personal relationships, and criteria that favor particular relationships, to influence the decisions of authority figures (Redding, 1990: 135). Chen, Farh, \& Tsui noted that in Chinese societies in general, “...employee loyalty is less likely to be based on their personal liking to the supervisor or their value congruence with the supervisor, but more based on shared attributes and gratitude toward individualized support by the supervisor, and personal obligations" (1998: J2).

Because of the greater emphasis vertically collectivistic cultures place on hierarchical than on lateral relationships for coordination and control, in such cultures it may be less important for subordinates to demonstrate a facility for effective interaction with peers in order to be assessed as meriting promotion to management . Rather, when collectivistic norms prevail, a disposition to be directive and cooperate fully with bosses is of greater importance to advancement (Triandis, 1998). Recent research on Chinese supervisor-subordinate dyads has 
found that social background similarities, labeled 'guanxi,' as well as demographic similarities, are significant determinants of subordinates' success (Farh et al., 1998; Tsui \& Farh, 1997; Xin \& Pearce, 1996). Within the similarity - attraction model, as power relationships become more asymmetric (as they are in collectivistic cultures), power-holders seek to increase their social status by developing high quality relationships with subordinates who are similar to themselves (see Jackson, et al., 1991; Tsui \& O’Reilly, 1989). Managers in collectivistic cultures may be particularly motivated to invest in relationships with subordinates who are similar to themselves because the shared attributes provide some assurance that their mutual obligations and understandings will outlast the authority-based relationship. The concept of mutual obligation in authority-based relationships is very strictly limited to the role context in collectivistic cultures, and thus trait inferences figure prominently in managers' expectations about subordinates' behavior in future roles. The two vertical relationship variables we hypothesized to mediate supervisor/subordinate similarity effects on promotion decisions (LMX and supervisor communication) both reflect the development of cooperative relationships between supervisors and subordinates. Therefore we predicted that supervisor/subordinate personality similarity will have a stronger influence on LMX and supervisor communication among the more collectivistic work unit cultures.

Because harmonious relationships based upon reciprocal obligation between leaders and followers are more central in collectivistic cultures, we also predicted that LMX and supervisor communication would be more strongly related to supervisor ratings of job performance in more collectivistic work unit cultures compared to more individualistic subunit cultures. In addition, we expect that supervisors' performance ratings have more influence on promotion decisions made by committee in the more collectivistic work unit cultures because of the higher primacy 
they place on supervisors' opinions of their subordinates. By extension from the stronger relationships between supervisor/subordinate similarity and behavioral integration and the stronger effects of behavioral integration and performance on promotion decisions that we predicted above, supervisor/subordinate personality similarity is predicted to more strongly influence advancement in more collectivistic subunit cultures.

Hypothesis 6 . The effects of supervisor/subordinate personality similarity on promotion decisions will be moderated by individualism-collectivism.

Hypothesis 6a. The effects of supervisor/subordinate personality similarity on LMX, supervisor communication, and performance will be stronger in collectivistic work unit cultures.

Hypothesis $6 \mathrm{~b}$. The effects of LMX, supervisor communication, and performance on promotion decisions will be stronger in collectivistic work unit cultures.

Hypothesis $6 \mathrm{c}$. Job performance ratings will partially mediate the effects of LMX and supervisor communication on promotion decisions.

Figure 1 provides a general overview of the relationships hypothesized in the study. The present study sampled promotion candidates from the same job and organization who were located in two different societies that differ substantially on I-C (i.e., Hong Kong and United States). We examined work unit-level I-C. Thus a considerable range of I-C was measured by capturing variation in I-C at both the societal and work unit levels.

insert Figure 1 about here

\section{METHODS}

\section{Sample and Procedures}


Tellers in Hong Kong (HK) and the U.S. employed by the same multinational bank, and their direct report supervisors, were administered a questionnaire two months prior to bank-wide decisions concerning which tellers would be promoted to teller supervisor. The HK and U.S. samples included 403 and 193 tellers, respectively. The final analysis sample was comprised of 386 and 185 tellers. The difference was due to tellers being omitted from the analyses (17 in the HK sample and eight in the U.S. sample) because they had fewer than two years working at the bank and therefore were ineligible for promotion. These persons nevertheless provided complete questionnaire data and their responses were used in calculating work unit peer personality similarity indexes and work unit individualism-collectivism. All of the Hong Kong tellers were ethnic Chinese, and $87 \%$ were women. The U.S. analysis sample was predominantly of Caucasian race (74\%), but other ethnic groups were represented, including $16 \%$ of Asian heritage; $83 \%$ were women. All participants were born in the country they were employed and most (93\% of HK sample and $89.7 \%$ of U.S. sample) had some college education.

The bank maintained a stable promotion system for its tellers worldwide. About every two years, all tellers were evaluated for promotion to teller supervisor. Promotion decisions were made by committees composed of the candidate's supervisor, other supervisors in the same branch, and a representative from central HR. Decisions were based upon the written and oral testimony of the immediate supervisor, his or her previous performance ratings, some objective performance data (i.e., cash drawer underages and overages, attendance, lateness), and input from the other managers. In the U.S. sample, 1 (3\%) of the supervisory work units had 3 tellers promoted, $5(13 \%)$ had 2 tellers promoted, $18(46 \%)$ had one teller promoted, and $15(38 \%)$ had no tellers promoted. In the HK sample 7 work units (9\%) had 2 tellers promoted, $45(56 \%)$ had 
one teller promoted, and $29(36 \%)$ had no tellers promoted. In the HK sample, $15.3 \%$ of the tellers were promoted, and $16.8 \%$ were promoted in the U.S. sample $\left(\chi^{2}(1)=0.10, \mathrm{~ns}\right)$.

Branches were divided into units reporting to a single teller supervisor who in turn reported to an operating supervisor. In the U.S. sample there were 39 supervisory units within 19 branches. Two of these units had four tellers but all others had five tellers. The HK sample included 81 supervisory work units within 38 branches; two supervisory units contained six tellers, four contained four tellers, and the rest contained five tellers. These branches were selected for the study because they were of similar size, age of establishment, and walk-in customer volume. Although participation in the survey was strictly and expressly voluntary and participants provided informed consent, a 100\% response rate on the questionnaire was obtained from the units that participated in the study. Three units in the U.S. and five units in Hong Kong did not participate because at least one member was not able to complete the questionnaire owing to illness or other reasons for unavailability. As all groups needed to be completely represented to provide accurate indexes of similarity, these units' data were not collected. Thus the effective response rates were $94 \%$ in Hong Kong and $92 \%$ in the U.S. The items were written in Chinese for HK participants. The conventional method of back-translation (Brislin, 1983) was used to translate the measures. The translators were professionals with college education in Chinese translation.

\section{Measures}

Job performance, peer integration, $L M X$, and supervisor communication. As part of a semi-annual performance appraisal conducted for both developmental and personnel action purposes, overall job performance was rated with a single item by each supervisor at about the same time other measures were obtained (i.e., two months prior to decision). This item had a 
five-point continuum ranging from unsatisfactory (1) to outstanding (5). Peer integration was measured using a four-item instrument adapted from Smith et al. (1994) and Shaw (1981). (e.g., "You do not get along well with the other members of your unit." (reverse-scored)). Eight items adapted from the same sources indexed supervisor communication (e.g., "You can communicate very effectively with the supervisor in your unit."; "You are always ready to cooperate with the supervisor of your unit."). Leader-member exchange (LMX) was measured using the candidate's responses to the seven-item index modified by Graen \& Uhl-Bien (1995; LMX-7). This instrument was purported by the authors to measure trust, respect, and perceived obligation to the supervisor, in addition to understanding, commitment, loyalty, reciprocal influence, and support (see Schriesheim, Castro, \& Cogliser, 1999). Sample items include, "It is very likely my team supervisor would use his/her power to help me solve problems at work."; "I have enough confidence in my team supervisor that I would defend and justify his/her decision if he/she were not present to do so.”)

Personality. Individualism-collectivism (I-C) was measured by a 16-item instrument developed by Earley (1993; e.g., "I would rather depend on myself than others."; "If a coworker were to receive a prize, I would feel proud.” (reverse-scored)). Higher scores indicate higher individualism and lower collectivism.

The short form (Form G) Myers-Briggs Type Indicator (MBTI; Myers, 1987) contains 96 items covering four personality constructs: Extroversion-introversion (E-I; ; KR20 = .87, US; $.88, \mathrm{HK})$, Sensing-iNtuiting $(\mathrm{S}-\mathrm{N} ; \mathrm{KR} 20=.90$, US; .8,8 HK), Thinking-Feeling (T-F; KR20 = .91 , US; .89, HK), and Judging-Perceiving (J-P; KR20 = .89, US; .90, HK). The items allow for "yes" or "no" answers. These are summed to form quantitative scales. E-I refers to the extent one focuses energy and attention on the outer world of people and things rather than personal 
ideas and impressions (“Are you (A) reserved (B) talkative?" (reverse-scored)). S-N refers to the extent one prefers to focus on the present time and on information obtained through one's senses rather than on the future and patterns and possibilities (e.g., "If you were a teacher, would you rather teach (A) fact courses, or (B) courses involving theory?"). Persons who score high on T-F tend to use logical principles and analyses of causes and effects rather than personal values and subjective impressions in decision making (e.g., "Do you more often let (A) your heart rule your head or (B) your head rule your heart?" (reverse-scored)). J-P refers to a preference for a planned and organized approach to life versus being flexible and spontaneous (e.g., "When you go somewhere for the day, would you rather (A) plan what you will do and when or (B) just go?").

The MBTI was developed to provide insights about personal style in interacting with others. For this reason the four dimensions of personality it measures were suitable for examining how similarity affects interpersonal interaction in ways that might lead to favorable or unfavorable social outcomes. Recent studies have shown that the MBTI has very favorable predictive and construct validity in work settings, and the indexes converge with Big 5 indexes to a considerable extent. It has also demonstrated reliability and nomological validity in both Chinese and 'Western' settings (see Furnham \& Stringfield, 1993).

Work unit culture differences. The I-C scores were aggregated to the work unit level, subtracting the candidate's own I-C composite score. After aggregating to the work unit level, the first principal component of the 16 items explained $53.7 \%$ of the variance (eigenvalue $=$ 8.60 ) and the item loadings ranged from .68 to .81 . Within-group agreement was estimated using the method $\left(r_{\mathrm{wg}}\right)$ developed by James, Demaree, and Wolf (1993). The mean $r_{\mathrm{wg}}$ coefficient across groups was .91 for I-C, demonstrating strong within-group agreement. To test between- 
groups differences, a within and between analysis (WABA) was conducted. The E ratio was 1.30 $(\mathrm{F}=4.09, \mathrm{df}=119,477, \mathrm{p}<.01)$. These analyses indicate substantial homogeneity within-groups and heterogeneity between work units in composite I-C scores.

Peer and supervisor/subordinate personality similarity. To examine peer personality similarity, we contrasted each candidate's composite personality scores (i.e., the four MBTI variables and I-C) with the corresponding index for each work unit peer using the Euclidean distance index (D). This index is commonly used in relational demography research (e.g., Tsui, Egan, \& O’Reilly, 1992):

$$
\mathrm{D}=\left[1 / \mathrm{n} \Sigma_{\mathrm{k}} \Sigma_{\mathrm{jn}}\left(\mathrm{x}-\mathrm{x}_{\mathrm{ij}}\right)^{2}\right]^{1 / 2}
$$

where $\mathrm{x}$ is the candidate's score on the kth personality dimension, the $\mathrm{x}_{\mathrm{ij}}$ are each work unit peer's corresponding score, and $\mathrm{n}$ is the number of peers in the jth supervisory work unit. Reversing this score provided the index of similarity. Supervisor/subordinate personality similarity was also indexed by this formula, except that $\mathrm{x}_{\mathrm{j}}$ was in this case the supervisor's personality score (cf. Tsui \& O’Reilly, 1989). For both supervisor/subordinate and peer similarity indexes, the reverse-scored D scores were centered around the mean for each work unit.

Control variables. As in other studies of promotions (e.g., Powell \& Butterfield, 1994) the demographic control variables were age, organization tenure (in years), education (in years), and gender. Because much previous research on worker similarity has focused on demographic similarity (e.g., Chatman et al., 1998; Jackson et al., 1991; K.G. Smith et al., 1994; Tsui et al., 1992), we controlled for this type of similarity by incorporating supervisor/subordinate and peer similarity indices on age, tenure, education, and gender. These indices were constructed using the (reversed) distance formula described above. 


\section{RESULTS}

A confirmatory factor analysis using LISREL 8 tested the expected factor structure on the Hong Kong data and compared this factor structure to the original, English language versions of the multi-item instruments from the U.S. sample. A test of a three-factor model (LMX, supervisor communication, and peer integration) across both groups yielded a good fit. Both the Comparative Fit Index (CFI) and the Incremental Fit Index (IFI) were .94. This indicated that the factor structure, specifying unidimensionality of all constructs, was consistent with the data across the two nations. When the factor covariances were constrained to be equivalent, a nonsignificant increase of the $\chi^{2}$ statistic was observed $\left(\Delta \chi^{2}=5.17, \mathrm{df}=6, \mathrm{~ns}\right)$ and the CFI and IFI indexes remained the same. These results indicate that relevant measurement properties of the indexes were statistically equivalent across the two samples.

Table 1 presents correlations among the analysis variables and descriptive statistics for the HK and U.S. samples. In addition to the statistical similarity on proportions of promotees noted above, the two samples did not differ significantly on age $(\mathrm{t}=.67, \mathrm{~ns})$ or gender $\left(\chi^{2}(1)=\right.$ $2.26, \mathrm{~ns})$. The HK candidates had significantly more years of education than the U.S. candidates $(t=-2.36, p<.05)$ and higher performance ratings $(t(594)=-5.69, p<.0001)$. On individualism- collectivism (I-C), the two samples differed significantly in the directions expected based on past research comparing HK Chinese and American samples (see P.B. Smith, Dugan, \& Trompenaars, 1996), with HK participants reporting lower I-C $(t(594)=24.57, p<$ .0001). The two samples did not differ on mean levels on LMX, supervisor communication, or peer integration.

insert Table 1 about here 
We first tested an omnibus logistic regression model in which promotion decision was regressed on the demographic variables, nation, work unit I-C, the eight indices of demographic similarity, both types of personality similarity index (supervisor/subordinate and peer), and interactions between similarity and I-C. The demographic variables, nation, and work unit I-C were entered at the first step and the demographic similarity variables at the second step. Neither of these two blocks was significantly related to promotion decisions, and only the tenure main effect was a significant predictor. Both supervisor/subordinate and peer personality similarity were entered at Step 3. This block was significant $(p<.00001)$, but whereas supervisor/subordinate personality similarity was a significant predictor of promotion decisions $(p<.00001)$, peer personality similarity was not. Thus Hypothesis 1 , predicting peer personality similarity effects across the entire sample, was rejected, as was the related hypothesis of mediating effects (Hypothesis 2) by extension. Hypothesis 3, concerning supervisor/subordinate personality similarity effects, was supported. For the purpose of completely controlling for the demographic control variables, the residuals from a logistic regression including the five control variables were regressed (using ordinary least squares (OLS)) on the eight demographic similarity variables at the first step, followed by the personality similarity variables in the next block, and finally the block of work unit I-C X personality similarity product term variables. As shown in Table 2 (Model 1), the findings were essentially identical to the logistic regression analyses with respect to Hypotheses 1 and 3.

Tests of mediation followed procedures outlined by Baron \& Kenny (1986), using the promotion decision residuals as described above. The effect of supervisor/subordinate personality similarity on promotion decisions was partially mediated by LMX and supervisor communication, but not job performance. The apparent mediating effect is partial only, because 
whereas the influence of supervisor personality similarity on promotion decisions was significantly attenuated after entering LMX and supervisor communication into the equation, its effect remained significant (see Table 2, Model 2; $p<.01$ ). Although job performance was significantly related to promotion decisions $(\mathrm{r}=.44, p<.0001)$, supervisor/subordinate personality similarity was not associated with performance (see Table 3 ). In a separate analysis (Model 3) the dependent variable was the residual from regressing (using logistic regression) promotion decisions on job performance as well as the five control variables. The influences of LMX and supervisor communication on promotion decisions were partially mediated by performance. Peer integration $(p<.01), \operatorname{LMX}(p<.0001)$ and supervisor communication $(p<$ .05) were significantly and positively related to performance after controlling for demographic main effects, demographic dissimilarity, work unit $\mathrm{I}-\mathrm{C}$, and nation $\left(\Delta \mathrm{R}^{2}=.042, F(3,552)=8.99\right.$, $p<.0001)$. These variables' influence on promotion decisions after performance was not controlled (Model 3) was substantially weaker compared to when performance was controlled ( $p$ $<.001)$. Thus Hypothesis 4, concerning partial mediating effects relating supervisor/subordinate personality similarity to promotion decisions, was partially supported.

insert Table 2 about here

Next, we tested the moderating influence of work unit I-C (yppotheses 5 and 6$)$. To do this we first tested the two I-C X personality similarity product terms in predicting promotion decisions. After all main effects were entered in a logistic regression analysis, the block of product terms was significantly related to promotion decisions (change in Cox \& Snell $\mathrm{R}^{2}=.037$, $\left.\chi^{2}(2)=23.71, p<.0001\right)$. The same result was found in an OLS analysis predicting the residualized (by the five demographic control variables) promotion decisions variable (Model 1). 
Each personality similarity $\mathrm{X}$ work unit I-C product term variable was a significant predictor in both the OLS and the logistic regression analyses. After dividing the sample by median split on work unit I-C to define "individualistic" (high I-C) and "collectivistic" (low I-C) work unit cultures, separate regressions were run. After controlling for supervisor/subordinate personality similarity and the other variables, the candidates in more individualistic work unit cultures demonstrated positive effects of peer personality similarity on promotion decisions (change in Cox \& Snell $\left.\mathrm{R}^{2}=.023, \chi^{2}(1)=7.11, p<.01\right)$ but there was no relationship between these variables in more collectivistic subunit cultures. These findings supported Hypothesis 5. Supervisor/subordinate personality similarity was entered after all other variables, including peer personality similarity. Although supervisor/subordinate similarity had a positive influence on promotion decisions across levels of work unit I-C, this effect was stronger in more collectivistic subunit cultures (change in Cox $\&$ Snell $\mathrm{R}^{2}=.131, \chi^{2}(1)=42.03, p<.00001$ ) than in individualistic subunit cultures (change in Cox $\&$ Snell $\mathrm{R}^{2}=.004, \chi^{2}(1)=1.18, \mathrm{~ns}$ ). The latter findings are consistent with $\underline{\text { Hypothesis } 6}$.

\section{insert Table 3 about here}

Hypotheses 5a and 6a predicted that the magnitude of relationships between peer personality similarity and supervisor/subordinate personality similarity, respectively, and their effects on the hypothesized mediating variables, would be moderated by work unit I-C. As shown in Table 3, there were no main or interactive effects of supervisor/subordinate or peer personality similarity on job performance. In testing Hypotheses 5a and 6a, the focal personality similarity variable (e.g., peer personality similarity) was entered after the corresponding personality similarity variable (e.g., supervisor/subordinate personality similarity) in a logistic 
regression analysis. Peer personality similarity was significantly related to peer integration in the overall sample $(p<.001)$. This relationship was moderated by work unit I-C $(p<.05)$; the relationship was significant in the more individualistic work unit cultures $\left(\Delta \mathrm{R}^{2}=.099, F(1\right.$, $274)=31.57, p<.0001)$ but not in more collectivistic unit cultures $\left(\Delta \mathrm{R}^{2}=.004, F(1,265)=1.21\right.$, ns). This supported Hypothesis 5a. Supervisor/subordinate personality similarity was positively associated with LMX and supervisor communication across levels of work unit I-C $(p<.001)$. Only the effect on supervisor communication, however, was stronger in collectivistic unit cultures $\left(\Delta \mathrm{R}^{2}=.050, F(1,265)=15.61, p<.0001\right)$ than in individualistic unit cultures $\left(\Delta \mathrm{R}^{2}=\right.$ $.012, F(1,274)=3.53, \mathrm{~ns})$. These findings regarding supervisor communication provide partial support for Hypothesis 6a. The significant peer personality similarity $\mathrm{X}$ work unit culture interaction predicting LMX (see Table 3) had not been hypothesized. The effect of peer personality similarity on LMX was positive among the more individualistic work unit cultures $(b$ $=.13, p<.01)$, whereas the same effect was not significant among collectivistic subunit cultures $(b=-.01, \mathrm{~ns})$.

Hypotheses $5 \mathrm{~b}$ and $6 \mathrm{~b}$ predicted stronger effects of the hypothesized mediating variables on promotion decisions depending on work unit I-C. The four mediating variables were significantly related to promotion decisions in logistic regression analyses (change in Cox \& Snell $\left.\mathrm{R}^{2}=.269, \chi^{2}(4)=185.18, p<.0001\right)$, and their respective product terms with I-C were also significant as a block (change in Cox \& Snell $\mathrm{R}^{2}=.016, \chi^{2}(4)=13.46, p<.01$ ). Whereas each of the four variables was significantly related to promotion decisions, only the effects of peer integration $(\mathrm{p}<.001)$ and supervisor communication $(p<.0001)$ were moderated by work unit IC. In testing Hypotheses $5 \mathrm{~b}$ and $6 \mathrm{~b}$, the focal independent variable (e.g., peer integration) was entered into the equation after the other hypothesized mediators (e.g., performance, LMX, 
supervisor communication). Consistent with $\underline{\text { Hypothesis } 5 \mathrm{~b}}$, peer integration was significantly related to promotion decisions in individualistic work unit cultures (change in Cox \& Snell $\mathrm{R}^{2}=$ $.016, \chi^{2}(1)=1.49, \mathrm{~ns}$ ) but not in collectivistic subunit cultures (change in Cox \& Snell $\mathrm{R}^{2}=.003$, $\left.\chi^{2}(1)=6.26, p<.01\right)$. In partial support of $\underline{\text { Hypothesis } 6 \mathrm{~b}}$, supervisor communication was more strongly related to promotion decisions in collectivistic work unit cultures (change in Cox \& Snell $\left.\mathrm{R}^{2}=.101, \chi^{2}(1)=43.62, p<.0001\right)$ than in individualistic unit cultures (change in Cox $\&$ Snell $\left.\mathrm{R}^{2}=.006, \chi^{2}(1)=2.41, \mathrm{~ns}\right)$.

Hypothesis 5c stated that among individualistic work unit cultures the effects of behavioral integration with peers on promotion decisions would be mediated by performance ratings. Performance ratings were strongly related to promotion decisions in both the more individualistic and the more collectivistic work unit cultures $(p<.0001)$. After controlling for performance and the five demographic control variables (as in Model 3 in Table 2) and then entering the block of demographic similarity variables, the block including LMX, supervisor communication, and peer integration was significantly related to the promotion decisions residual in individualistic work unit cultures $\left(\Delta \mathrm{R}^{2}=.090, F(3,278)=9.36, p<.001\right)$. This block was more strongly related to the residualized promotion decisions variable when performance was not controlled for $\left(\Delta \mathrm{R}^{2}=.120, F(3,278)=13.18, p<.0001\right)$, but the effect of peer integration on the promotion residual was not significantly lower when performance was controlled for compared to when it was not. Thus Hypothesis $5 \mathrm{c}$ was not supported. In testing the parallel Hypothesis 6c, the effects of supervisor communication and LMX on promotion decisions were examined in collectivistic work unit cultures. The block including peer integration, LMX, and supervisor communication was significant when performance was not controlled $\left(\Delta \mathrm{R}^{2}=.289\right.$, $F(3,269)=36.81, p<.0001)$, and the overall block effect had a significantly smaller effect when 
performance was controlled $\left(\Delta \mathrm{R}^{2}=.198, F(3,269)=22.62, p<.0001\right)$. In the latter model (equivalent to Model 3 in Table 2) the effects of LMX and supervisor communication were significantly reduced $(p<.01)$ relative to the model in which performance was not controlled. These findings support Hypothesis 6c.

A set of post hoc logistic regression analyses examined how differences in societal culture (Hong Kong versus U.S.) corresponded to the work unit I-C moderating effects in predicting promotion decisions. The nation $\mathrm{X}$ supervisor/subordinate personality similarity and nation X peer personality similarity product terms were entered as a block after the two corresponding personality similarity X work unit I-C product terms. The nation X similarity effects were significant (change in Cox \& Snell $\mathrm{R}^{2}=.037, \chi^{2}(2)=23.71, p<.0001$ ) but their effects were weaker than when the IC X similarity interactions had not been controlled (i.e., change in Cox \& Snell $\left.\mathrm{R}^{2}=.071, \chi^{2}(2)=45.53, p<.00001\right)$. After controlling for the four hypothesized mediating variables, the nation $\mathrm{X}$ supervisor/subordinate personality similarity coefficient was no longer significantly related to promotion decisions, whereas the nation $\mathrm{X}$ peer personality similarity coefficient remained significant $(p<.01)$. There was also evidence of meaningful variation across work unit cultures within the HK sub-sample. The unit I-C X supervisor/subordinate personality variable was significantly related to promotion decisions after controlling for all main effects within the HK sub-sample $(p<.05)$ but not in the smaller U.S. sub-sample. The I-C X peer personality similarity effect was not significant within either subsample.

To more thoroughly explore the significant interactive relationship between peer personality similarity and work unit I-C predicting LMX, we examined the effects of peer integration on LMX. Peer integration was positively related to LMX in individualistic subunit 
cultures $(p<.001)$ but not in the more collectivistic subunit cultures. After controlling for peer integration in the sub-sample composed of more individualistic work units, the relationship between peer personality similarity and LMX was no longer significant.

\section{DISCUSSION}

\section{Key Findings and Theoretical Interpretations}

It appears that whereas personality similarity was a biasing factor regardless of cultural context, whether the critical similarity was with one's peers or with the supervisor depended upon whether norms of individualism or collectivism prevailed in the work unit. The crossnational nature of our sample enabled us to measure a broad range of work unit I-C. Hong Kong society is very collectivistic and U.S. society is very individualistic. Indeed, two-thirds of the Hong Kong units had lower scores on I-C than the lowest scoring U.S. unit, and the most individualistic Hong Kong unit fell at the $32^{\text {nd }}$ percentile of the U.S. distribution. Within each of these societies we sampled, however, there was also a substantial range of work unit I-C. Nevertheless, among the more collectivistic units it can be presumed that the collectivism respondents reported was strongly influenced by Chinese cultural norms, just as the more individualistic unit members were influenced strongly by U.S. cultural norms. The use of particularistic criteria in decision-making (i.e., personalism) is accepted if not encouraged in collectivistic cultures (Bond \& Hwang, 1995; Farh et al., 1998). Thus the particularistic norms that are supported within these cultures may explain why stronger supervisor/subordinate personality similarity effects were observed a) in the Hong Kong sample compared to the U.S. sample; and b) when comparing the Hong Kong sub-sample with higher collectivistic norms with the Hong Kong units whose members reported lower collectivism and higher individualism (i.e., lower and higher by standard of the Hong Kong sample). 
It is less clear, however, whether these apparent similarity - attraction effects reflect supervisors' motivational biases, informational biases, or both. With respect to surface-level similarity, some studies suggest that managers use their influence over promotion decisions as a means to advance their own agendas (Jackson, et al., 1991; Kanter, 1977; Tsui \& O'Reilly, 1989) or they apply self-serving schemas to judge promotability (Wayne et al., 1997). Both of these are motivational biases. The stronger influence of supervisor/subordinate personality similarity on personnel decisions in the more collectivistic unit cultures supports a motivational bias interpretation of the findings. Conversely, the effect of LMX on promotion decisions was equally strong across the range of work unit cultures. Regardless of work unit I-C, supervisors were more likely to form trusting, high commitment relationships with subordinates who were similar to them in personality. A favorable LMX is seen as an outgrowth of mutual advantages that are perceived by the parties in pursuing a high trust relationship, and thus the motivational bias one may attribute to supervisor/subordinate similarity from our findings would appear to be a pan-cultural phenomenon. Subordinates who perceive a very favorable leader-member exchange will also have more opportunities to demonstrate their potential to the supervisor. This could foster an informational bias among supervisors toward recommending subordinates who are similar to themselves for promotion, because these subordinates' successes may be more available in their supervisors' memories when promotion decisions are made. Thus, the entire pattern of findings supports a combination of motivational and informational biases influencing the relationship between supervisor/subordinate personality similarity and promotion decisions. Future research conducted under more controlled conditions could more precisely identify the underlying psychological processes. 
On the other hand, candidates' perceptions of peer integration influenced promotion decisions only in the more individualistic work units. The key difference between cultures lay in their relative emphasis on vertical and horizontal relationships. What supervisors and/or other promotion committee members in individualistic work unit cultures observed in candidates' peer relations may have affected their assessments of social skills that are needed to be an effective first-line supervisor. Because there is less pressure to be cooperative in individualistic cultures, the greater potential for conflicts and coordination difficulties may demand more supervisory attention in these contexts. Smooth interaction with peers may signal a social skill that is critical for supervision in an individualistic culture. Managers may thus be rationally motivated to mark for advancement those persons who can best interact with peers, because they may manage more successfully in environments that place less reliance on hierarchical relationships and formal authority than on lateral relationships and informal influence.

\section{Limitations and Directions for Future Research}

Future studies that include large samples from multiple cultures could extend and refine this research. A multi-nationality study examining different dimensions of culture besides I-C may facilitate a more complete understanding of the sociological and psychological processes underlying relationships between personality similarity and promotion. Future studies should also examine different types of jobs and different types of promotion decisions. The present sample of tellers was occupationally homogeneous and thus quite easily matched across cultures. In addition, as a non-elite occupation there was little prior 'homosocial reproduction' (Kanter, 1977) that would restrict the ranges of similarity among participants. The single organizational context may also affect generalizability of these findings. We predicted that job performance would exhibit stronger effects on promotion decisions in more collectivistic work unit cultures, 
but its relationship with promotion decisions did not vary across cultural contexts. Within a larger population of organizations, explicit or implicit policies which affect the strength of relationship between evaluation criteria and promotion decisions may be more diverse, and thus the potential for sub-sample differences in relationships between criteria and promotion decisions may be greater.

This study indicates that the mediating effects of perceived qualities of behavioral integration with peers and the supervisor extend to personality similarity and its relationships with promotion decisions. The relational demography research has been acknowledged to measure only proxies for behavioral similarity (see Pfeffer, 1983), whereas the traits we measured would seem to reflect more directly on processes linking behavioral similarity to integration. Moreover, we controlled for a range of demographic similarity indices commonly examined in the organizational demography literature. None of the eight demographic similarity variables we examined was associated with promotion decisions or performance ratings, and only a few were associated with behavioral integration with peers or the supervisor. As suggested by attraction-selection-attrition (ASA; Schneider et al., 1995), adaptation (Kohn \& Schooler, 1982), and group entrainment (Reid-Fraser \& Reed, 2000) perspectives on how the distribution of worker traits evolves within a work unit, there may be processes within organizational units that encourage workers to have more similar traits. Given that personality is quite stable during adulthood, then, like demographic similarity, personality similarity may under-represent mean levels of behavioral similarity among coworkers. It could also be that as quality of behavioral integration improves or deteriorates within a supervisor/subordinate dyad or a work group for other reasons, behavioral similarity may change as an outcome. Coworkers' entries into and departures from their positions are events that may influence behavioral 
similarity positively (as in ASA) or negatively (as within entrainment and adaptation perspectives). More compelling inferences about these processes could be made using detailed observational methodologies in which actual behavior and communication patterns (as in the Chatman et al. (1998) study) are tracked over time and related to these entry and departure events.

Organizational research on behavioral/trait similarity may also benefit from examining the role of informal social status among peers. Previous research suggests that behavioral similarity to peers often increases a person's social status in the group (Wright, et al., 1986). It seems plausible that personality similarity to peers influenced promotion decisions in individualistic cultures in this study because individuals who were more similar to their peers gained status among them. This status conferred lateral influence that made them appear to be higher potential leaders and thus more promotable. We had not hypothesized the significant positive relationship between peer personality similarity and LMX that was limited to more individualistic work unit cultures. This relationship appeared to be mediated by the candidate's perception of his or her integration with peers. These findings further suggest how supervisors in collectivistic work unit cultures may look with less favor upon qualities of peer interaction in collectivistic work unit cultures. In collectivistic cultures, subordinates who have high influence with their peers may be seen as threatening to certain supervisors. These supervisors may be discouraged from entering into a trust-based relationship with these subordinates because their influence among peers may be seen as a threat to their own authority. In such cultures, individuals' subservience to authority is limited to the specific role and authority relationship they have at a given time. Thus when making advancement decisions supervisors must use other cues besides compliance, such as similarity to themselves, to predict how subordinates are likely 
to behave when they no longer report to them. Future studies could therefore profit by examining cultural moderators of relationships among peer social status, behavioral similarity, and advancement.

\section{Conclusions}

The key findings of this study related to differences between cultures in terms of the type of co-worker (supervisor or peer) with whom personality similarity was most beneficial to a promotion candidate. These influences of personality similarity were partially mediated by behavioral integration between the parties. From a descriptive perspective, the favoring of persons who are more similar to their work unit peers in promotion decisions, while not likely done consciously, may reflect decision makers' desires to identify potential managers who are most adept at limiting the adverse behavioral consequences of individualistic norms in interdependent task environments. But if the positive perceptions that lead to a favorable promotion decision are grounded on similarity to peers, there is no guarantee that the promotee will be equally similar to his or her new management peers or to those he or she may lead in the future. Thus the organizational benefits of promoting individuals on the basis of how they interact with their peers may prove illusory. Ideally, managers will endeavor to create stronger situations in which being similar to one's peers has a lesser influence on these outcomes. For example, as suggested by Chatman et al. (1998), efforts to encourage cooperative norms such as through group task design and group incentives might reduce the influence of peer similarity on valued outcomes.

From a management effectiveness perspective, the influence of supervisor/subordinate personality similarity on advancement is perhaps most troubling because it suggests that supervisors are biased toward promoting persons like themselves. Even in collectivistic cultural 
contexts, where this effect was most pronounced in our study, environments have become more complex and turbulent. Thus the motivation and ability to interact effectively in lateral relationships is increasingly important for organizational success. Incorporating peer evaluations into the promotion assessment process may help to reduce the role of supervisors' biases and shift decision makers' attention to attributes of broader merit for management success.

Regardless of the cultural context, reducing supervisory biases in promotion recommendations may be expected to enhance the validity and utility of this critical type of selection decision. By consciously avoiding simple biases in social perception, managers can facilitate more positive social equity perceptions and advance persons who will be most competent in leadership positions. 


\section{REFERENCES}

Baron, R.M., \& Kenny, D.A. 1986. The moderator-mediator variable distinction in social psychological research: Conceptual, strategic, and statistical considerations. Journal of Personality and Social Psychology, 51: 1173-1182.

Bond, M.H., \& Hwang, K.K. 1995. The social psychology of Chinese people. In M.H. Bond (Ed.), The psychology of the Chinese people. Hong Kong: Oxford University Press.

Brislin, R.W. 1980. Translation and content analysis of oral and written material. In H.C. Triandis, \& J.W. Berry (Eds.), Handbook of cross-cultural psychology, vol. 2: 349-444. Boston: Allyn and Bacon.

Byrne, D.E. 1971. The attraction paradigm. New York: Academic Press.

Chatman, J.A., \& Barsade, S.G. 1995. Personality, organizational culture, and cooperation: Evidence from a business simulation. Administrative Science Quarterly, 40: 423-443.

Chatman, J.A., \& Flynn, F.J. 2001. The influence of demographic heterogeneity on the emergence and consequences of cooperative norms in work teams. Academy of Management Journal, 44: 956-974.

Chatman, J.A., Polzer, J.T., Barsade, S.G., \& Neale, M.A. 1998. Being different yet feeling similar: The influence of demographic composition and organizational culture on work processes and outcomes. Administrative Science Quarterly, 43: 749-780.

Chen, Z.X., Farh, J.L., \& Tsui, A.S. 1998. Loyalty to supervisor, organizational commitment, and employee performance: The Chinese case. Best Papers Proceedings of the Academy of Management, OB: J1-J9.

Eagleson, G., Waldersee, R., \& Simmons, R. 2000. Leadership behavior similarity as a basis of selection into a management team. British Journal of Social Psychology, 39: 301-308. 
Earley, P.C. 1993. East meets West meets Mideast: Further explorations of collectivistic and individualistic work groups. Academy of Management Journal, 36: 319-348.

Erez, M., \& Earley, P.C. 1987. Comparative analysis of goal-setting strategies across cultures. Journal of Applied Psychology, 72: 658-665.

Farh, J.L., Tsui, A.S., Xin, K., \& Cheng, B. 1998. The influence of relational demography and Guanxi: The Chinese case. Organization Science, 9: 471-488.

Ferris, G.R., \& Judge, T.A. 1991. Personnel/human resources management: A political influence perspective. Journal of Management, 17: 447-488.

Fiske, A.P., Kitayama, S., Markus, H.R., \& Nisbett, R.E. 1998. The cultural matrix of social psychology. In D.T. Gilbert, S.T. Fiske, \& G. Lindzey (Eds.), The handbook of social psychology: 915-981. New York: McGraw-Hill.

Furnham, A., \& Stringfield, P. 1993. Personality and occupational behavior: Myers-Briggs type indicator correlates of managerial practices across cultures. Human Relations, 46: 827-849.

Graen, G.B., \& Uhl-Bien, M. 1995. Relationship-based approach to leadership: Development of leader-member exchange (LMX) theory of leadership over 25 years: Applying a multi-level multi-domain perspective. Leadership Quarterly, 6: 219-247.

Hambrick, D.C. 1994. Top management groups: A conceptual integration and reconsideration of the "team" label. In B.M. Staw \& L.L. Cummings (Eds.), Research in organizational behavior, vol. 16: 171-213. Greenwich, CT: JAI Press.

Harrison, D.A., Price, K.H. \& Bell, M.P. 1998. Beyond relational demography: Time and the effects of surface- and deep-level diversity on work group cohesion. Academy of Management Journal, 41: 96-107.

Hofstede, G. 1980. Culture's consequences. Beverly Hills, CA: Sage. 
Jackson, S., Brett, J., Sessa, V., Cooper, D., Julin, D., \& Peyronnin, K. 1991. Some differences make a difference: Individual dissimilarity and group heterogeneity as correlates of recruitment, promotions, and turnover. Journal of Applied Psychology, 76: 675-689.

James, E.H. 2000. Race-related differences in promotions and support: Underlying effects of human and social capital. Organization Science, 11: 493-508.

James, L.R., Demaree, R.G., \& Wolf, G. 1993. $\mathrm{r}_{\mathrm{wg}}$ : An assessement of within-group inter-rater agreement. Journal of Applied Psychology, 78:306-339.

Jehn, K.A., Northcraft, G.B., \& Neale, M.A. 1999. Why differences make a difference: A field study of diversity, conflict, and performance in workgroups. Administrative Science Quarterly, 44: 741-763.

Kanter, R. 1977. Men and women of the corporation. New York: Basic Books.

Kohn, M. L. \& Schooler, C. (1982). Job conditions and personality: A longitudinal assessment of their reciprocal effects. American Journal of Sociology, 87: 1257-1286.

Markham, W.T., Harlan, S.L., \& Hackett, E.J. 1987. Promotion opportunity in organizations: Causes and consequences. In G.R. Ferris \& K.M. Rowland (Eds.), Research in personnel and human resource management, 5: 223-287. Greenwich, CT: JAI Press.

Myers, I.B. 1987. Myers-Briggs Type Indicator, Form G. Palo Alto, CA: Consulting Psychologists Press.

Pfeffer, J. 1983. Organizational demography. In B.M. Staw \& L.L. Cummings (Eds.) Research in organizational behavior, vol. 5: 299-357. Englewood Cliffs, NJ: JAI Press.

Powell, G.N., \& Butterfield, D.A. 1994. Investigating the "glass ceiling" phenomenon: An empirical study of actual promotions to top management. Academy of Management Journal, 37: 68-86. 
Redding, S.G. 1990. The spirit of Chinese capitalism. Berlin: Walter de Gruyter.

Reid-Fraser, J.M., \& Reed, S. 2000. Cognitive entrainment in engineering design teams. Small Group Research, 31: 354-382

Schneider, B., Goldstein, H.W., \& Smith, D.B. 1995. The ASA framework: An update. Personnel Psychology, 48: 747-773.

Schriesheim, C.A., Castro, S.L., \& Cogliser, C.C. 1999. Leader-member exchange (LMX) research: A comprehensive review of theory, measurement, and data-analytic practices. Leadership Quarterly, 10: 63-113.

Shaw, M.E. 1981. Group dynamics: The psychology of small group behavior. ( ${ }^{\text {rd }}$ Ed.). New York: McGraw-Hill.

Shore, L.M. Shore, \& G.C. Thornton III, 1992. Construct validity of self- and peer evaluations of performance dimensions in an assessment center. Journal of Applied Psychology, 77: 42-54.

Smith, P.B., Dugan, S., \& Trompenaars, F. 1996. National culture and values of organizational employees: A dimensional analysis across 43 nations. Journal of Cross-Cultural Psychology, 27: 231-264.

Smith, P.B., Peterson, M.F., \& Wang, Z.M. 1996. The manager as mediator of alternative meanings. A pilot study from China, the USA and U.K. Journal of International Business Studies, 27: 115-137.

Smith, K.G., Smith, K.A., Olian, H.P., O’Bannon, D.P., \& Scully, J.A. 1994. Top management team demography and process: The role of social integration and communication. Administrative Science Quarterly, 39: 412-438.

Triandis, H.C. 1998. Vertical and horizontal individualism and collectivism: Theory and research implications for international comparative management. In J.C. Cheng \& R.B. 
Peterson (Eds.), Advances in international comparative management, vol. 12: 7-35. Stamford, CT: JAI Press.

Triandis, H.C., \& Gelfand, M.J. 1998. Converging measurement of horizontal and vertical individualism and collectivism. Journal of Personality and Social Psychology, 74: 118-128.

Trice, H.M., \& Beyer, J.M. 1993. The cultures of work organizations. Englewood Cliffs, NJ: Prentice Hall.

Tsui, A.S., \& Farh, J.L. 1997. Where gaunxi matters: Relational demography in the Chinese context. Work and Occupations, 24: 56-79.

Tsui, A., Egan, T.D., \& O’Reilly, C.A. 1992. Being different: Relational demography and organizational attachment. Administrative Science Quarterly, 37: 549-579.

Tsui, A., \& O'Reilly, C.A. 1989. Beyond simple demographic effects: The importance of relational demography in superior-subordinate dyads. Academy of Management Journal, 32: 402-423.

Turban, D.B., \& Jones, A.P. 1988. Supervisor-subordinate similarity: Types, effects, and mechanisms. Journal of Applied Psychology, 73: 228-234.

Wayne, S.J., Liden, R.C., Graf, L.F., \& Ferris, G.R. 1997. The role of upward influence tactics in human resource decisions. Personnel Psychology, 50: 979-1006.

Williams, K.Y., \& O’Reilly, C.A. 1998. Demography and diversity in organizations: A review of 40 years of research. In B.M. Staw (Ed.), Research in organizational behavior, vol. 20: 77140. Greenwich, CT: JAI Press.

Wright, J.C., Giammarino, M., \& Parad, H.W. 1986. Social status in small groups: Individualgroup similarity and the social "misfit." Journal of Personality and Social Psychology, 50: 523-536. 
Xin, K.R., and Pearce, J.L. 1996. Guanxi: Connections as substitutes for formal institutional support. Academy of Management Journal, 39: 1641-1658. 


\section{TABLE 1}

Means, Standard Deviations, and Correlations of Variables- Hong Kong and U.S. Samples

Hong Kong sample
1. Age
2. Education
3. Gender
(1=female; $2=$ male $)$
4. Work unit I-C
5. Peer personality similarity
6. Supervisor/subordinate
personality similarity
7. Promotion decision
8. Job performance
9. Leader-member exchange
10. Peer integration
11. Supervisor communication

$\begin{array}{lccccccccccc}\text { Mean } & \text { SD } & & & & & & & & & & \\ 25.32 & 1.52 & -- & & & & & & & & \\ 13.83 & 1.10 & .08 & -- & & & & & & & \\ 1.13 & 0.33 & .01 & .09 & -- & & & & & & \\ 3.52 & 0.24 & -.05 & -.02 & .09 & (.91) & & & & & \\ 0.04 & 0.10 & .04 & .01 & -.03 & -.11 & -- & & & & \\ 0.00 & 0.27 & .02 & .06 & .05 & -.23 & .36 & -- & & & \\ 0.15 & 0.36 & .01 & .13 & .01 & -.14 & -.00 & .34 & -- & & \\ 3.85 & 0.61 & -.02 & .13 & .07 & -.07 & -.02 & .13 & .48 & -- & & \\ 4.62 & 0.88 & -.02 & -.01 & -.02 & -.15 & .06 & .26 & .32 & .19 & (.94) \\ 2.14 & 0.67 & .04 & .05 & -.11 & -.09 & .14 & .06 & .04 & .04 & .06 & (.89) \\ 2.46 & 0.75 & .09 & .02 & .03 & -.21 & .07 & .28 & .49 & .27 & .19 & -.02\end{array}$

\section{U.S. sample}

1. Age
2. Education
3. Gender
$(1=$ female $2=$ male $)$
4. Work unit I-C
5. Peer personality similarity

$\begin{array}{ccccccc}25.40 & 1.52 & -- & & & \\ 13.60 & 1.05 & 0.05 & -- & & \\ 1.17 & 0.38 & .04 & .03 & -- & & \\ & & & & & & \\ 3.85 & 0.22 & -.12 & -.14 & -.16 & (.88) & \\ 0.04 & 0.10 & -.10 & -.11 & .02 & -.09 & --\end{array}$


TABLE 1 (Continued)

\begin{tabular}{|c|c|c|c|c|c|c|c|c|c|c|c|c|c|}
\hline & Mean & SD & 1 & 2 & 3 & 4 & 5 & 6 & 7 & 8 & 9 & 10 & 11 \\
\hline $\begin{array}{l}\text { 6. Supervisor/subordinate } \\
\text { personality similarity }\end{array}$ & -.01 & 0.27 & .13 & .02 & -.02 & -.29 & .13 & -- & & & & & \\
\hline 7. Promotion decision & 0.17 & 0.37 & -.04 & -.12 & -.09 & .01 & .29 & -.01 & -- & & & & \\
\hline 8. Job performance & 3.42 & 0.93 & -.05 & .01 & -.18 & .10 & .10 & -.05 & .44 & -- & & & \\
\hline 9. Leader-member exchange & 4.70 & 1.02 & -.01 & -.17 & -.09 & .01 & .21 & -.02 & .28 & .21 & $(.95)$ & & \\
\hline 10. Peer integration & 2.12 & 0.67 & -.06 & .02 & .08 & -.21 & .33 & .11 & .33 & .08 & .25 & $(.88)$ & \\
\hline 11. Supervisor communication & 2.46 & 0.71 & -.02 & .04 & -.02 & .06 & -.01 & -.02 & .02 & -.06 & .12 & .12 & $(.92$ \\
\hline
\end{tabular}

Hong Kong sample $\mathrm{n}=386$, critical $\mathrm{r}(\mathrm{p}<.05)=.10$; U.S. sample $\mathrm{n}=185$, critical $\mathrm{r}(\mathrm{p}<.05)=.15$ I-C = Individualism-collectivism (Higher scores connote higher individualism.) 
TABLE 2

\section{Regression Results-- Predicting Promotion Decision Residuals ${ }^{1}$}

Step 1:

Age similarity to supervisor

Tenure similarity to supervisor

Gender similarity to supervisor

Education level similarity to supervisor

Age similarity to peers

Tenure similarity to peers

Gender similarity to peers

Education level similarity to peers

\section{Change in $\mathbf{R}^{2}$}

Step 2:

Peer Integration

LMX

Supervisor communication

\section{Change in $\mathbf{R}^{2}$}

Step 3:

Peer Personality Similarity (PPS)

Supervisor Personality Similarity (SPS)

Change in $\mathbf{R}^{2}$
Model 1

.01

$-.05$

$-.02$

$-.03$

$-.06$

.06

.06

$-.01$

$\Delta \mathrm{R}^{2}=.008$,

$\mathrm{F}(8,561)=0.55$
Model 2

.01

$-.05$

$-.02$

$-.03$

$-.06$

.06

.06

$-.01$

$\Delta \mathrm{R}^{2}=.008$,

$\mathrm{F}(8,561)=0.55$
Model 3

.00

$-.03$

$-.03$

.01

$-.06$

.05

.02

.02

$\Delta \mathrm{R}^{2}=.005$,

$F(8,561)=0.32$

$.09 *$

.07

$-2.23 * * *$

$\mathrm{F}(3,558)=23.21 * * *$

$.29 * * *$

$\Delta \mathrm{R}^{2}=.17$,

$\Delta \mathrm{R}^{2}=.11$,

$\mathrm{F}(3,558)=37.85 * * *$

$.24 * * *$

$-$

.04

.01

$.11 * *$

$\Delta \mathrm{R}^{2}=.011$,

$\Delta \mathrm{R}^{2}=.041$,

$\mathrm{F}(2,559)=11.93 * * *$
.02

$.09 *$

$\Delta \mathrm{R}^{2}=.010$,

$\mathrm{F}(2,556)=3.30 *$

Step 4:

PPS X Work Unit I-C

\section{$1.61 * * *$}

$-2.43 * * *$

$\Delta \mathrm{R}^{2}=.043$,

$\mathrm{F}(2,557)=13.28 * * *$
$\mathrm{F}(2,556)=3.89 *$

$1.42 * *$

$-1.87 * * *$

$\Delta \mathrm{R}^{2}=.028$, $\mathrm{F}(2,554)=9.78 * * *$
$1.08^{*}$

$-1.58 * *$

$\Delta \mathrm{R}^{2}=.018$, $\mathrm{F}(2,554)=5.92 * *$

${ }^{1}$ The dependent variable for Models 1 and 2 is the residual from a model regressing promotion decision on age, gender, education, tenure, nation, and work unit I-C; the Model 3 dependent variable is the residual from a model regressing promotion decision on age, gender, education, tenure, nation, and work unit I-C, and performance. Essentially the same results were obtained when promotion decision $(0,1)$ was the dependent variable in logistic regression analyses.

$$
* p<.05
$$


TABLE 3

Hierarchical Regression Analyses Predicting Hypothesized Mediators

$\begin{array}{cccc}\text { Job } & \text { Peer } & \text { Leader- } & \text { Supervisor } \\ \text { Performance } & \text { Integration } & \begin{array}{c}\text { Member } \\ \text { Exchange }\end{array} & \text { Integration } \\ & & & \end{array}$

\begin{tabular}{|c|c|c|c|c|}
\hline Age & .04 & .07 & .02 & .09 \\
\hline Organization tenure & $-.11 *$ & -.11 & -.06 & -.07 \\
\hline Education & $.09 *$ & .05 & -.07 & .02 \\
\hline Gender $($ male $=1$, female $=2)$ & -.05 & -.05 & -.04 & .01 \\
\hline Work Unit Individualism-Collectivism (I- & .00 & $-.14 * *$ & $-.11 *$ & $-.14 * *$ \\
\hline Nation $(\mathrm{US}=1, \mathrm{HK}=2)$ & $.26 * * *$ & -.07 & -.09 & -.07 \\
\hline Contribution to $\mathbf{R}^{2}$ & $.086 * * *$ & $.024 *$ & .018 & .021 \\
\hline Age similarity to supervisor & .07 & .06 & .05 & -.15 \\
\hline Tenure similarity to supervisor & -.09 & -.04 & -.10 & .14 \\
\hline Gender similarity to supervisor & .04 & .07 & .03 & .11 \\
\hline Education level similarity to supervisor & -.01 & -.02 & $-.09 *$ & -.05 \\
\hline Age similarity to peers & -.01 & .02 & -.06 & .04 \\
\hline Tenure similarity to peers & .02 & -.04 & .08 & .07 \\
\hline Gender similarity to peers & .09 & $-.11 *$ & $.12 *$ & .09 \\
\hline Education level similarity to peers & -.02 & $.10^{*}$ & .03 & -.06 \\
\hline Contribution to $\mathbf{R}^{2}$ & .008 & .016 & .023 & .026 \\
\hline Peer Personality Similarity (PPS) &. .02 & $.20 * * *$ & .07 & -.01 \\
\hline Supervisor Personality Similarity (SPS) & .04 & -.01 & $.12 * *$ & $.16^{* * *}$ \\
\hline Contribution to $\mathbf{R}^{2}$ & .003 & $.037 * * *$ & $.024 * * *$ & $.024 * * *$ \\
\hline PD X I-C & .88 & $1.21 *$ & $1.78^{*}$ & .07 \\
\hline SD X I-C & -.73 & .22 & -.61 & $-1.97 * * *$ \\
\hline Contribution to $\mathbf{R}^{2}$ & .006 & $.010^{*}$ & .009 & $.023 * * *$ \\
\hline Total $\mathbf{R}^{2}$ & .103 & .087 & .074 & .094 \\
\hline $\begin{array}{r}* \mathrm{p}<.05 \\
* * \mathrm{p}<.01\end{array}$ & & & & \\
\hline$* * * \mathrm{p}<.001$ & $570 ; \mathrm{Co}$ & nts are star & dized. & \\
\hline
\end{tabular}




\section{FIGURE 1}

Relationships Between Personality Similarity and Promotion Decisions

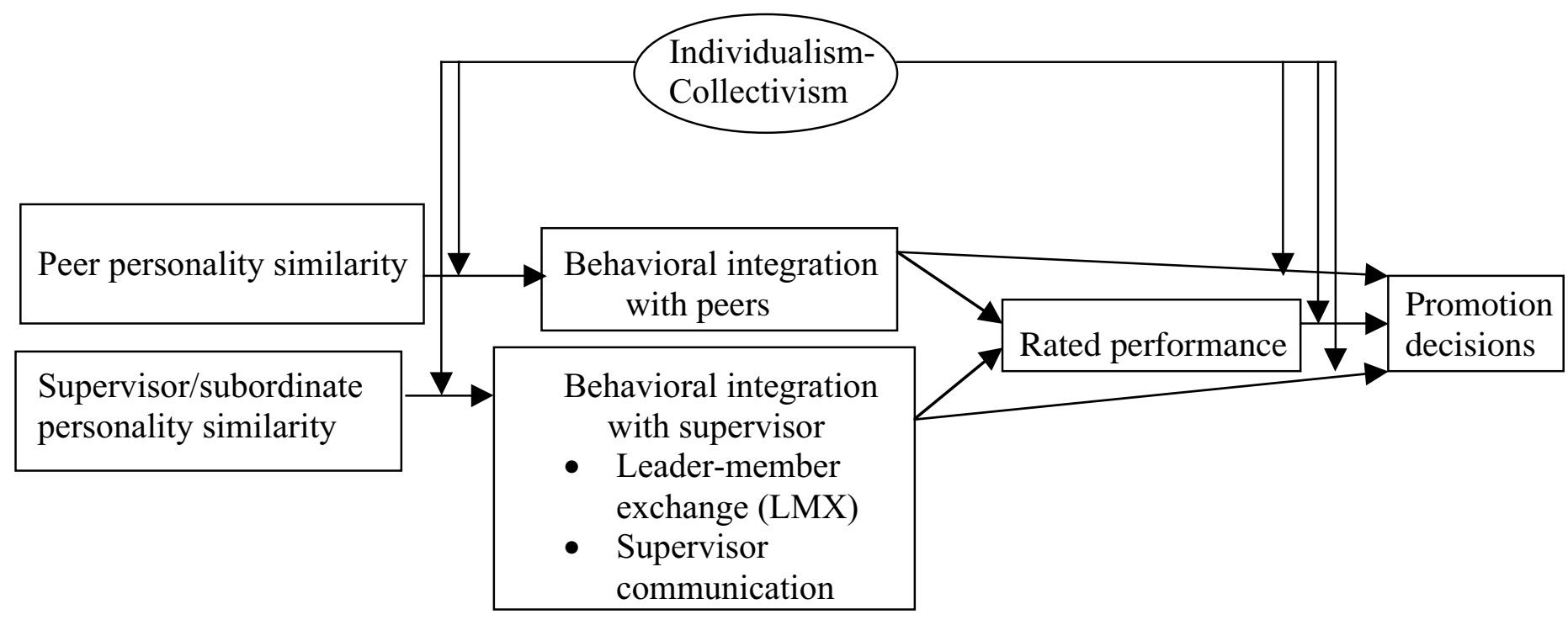




\section{Biographical Sketches}

John Schaubroeck (jms43@Drexel.edu) is a Professor of Management and Head of the Department of Management, LeBow College of Business, Drexel University. He received a Ph.D. in Organizational Behavior and Human Resource Management from Purdue University. His research interests include work stress and coping and cross-cultural issues in organizational behavior.

Simon S. K. Lam (imonlam@business.hku.hk) received his Ph.D. from Australian National University. He is an associate professor of management at the School of Business, University of Hong Kong. His research focuses on quality management, work-related commitments, and crosscultural human resource management. 